\title{
In Memoriam: Professor Robert L. Snyder
}

\section{September 2011}

It is with great sadness to inform you that Professor Robert L. Snyder passed away early on the morning of September 1st, 2011, from complications due to cancer. At the time of his death, Bob was Professor and Co-chair of the School of Materials Science and Engineering at Institute of Technology (Georgia Tech), a member of the Nanoscience and Nanotechnology Faculty (NanoTECH), and Chairman of the Denver X-ray Conference Organizing Committee. Bob leaves behind his loving wife of 48 years, Sheila, daughter Krissy, son Robert, and their families. Many of you personally knew Bob, as he was an ambassador of materials science and engineering as well as all types of $\mathrm{X}$-ray analysis during his lifetime. He made numerous friendships around the world and was generally known for his passion for life and the intensity and excellence of his science. The photographs that accompany this announcement were taken of Bob and friends from scientific events and conferences around the world.

Bob was born in Plattsburg, New York in 1941. He received his B.A. in Chemistry from Marist College and his Ph.D. from Fordham University in 1968. He entered the field of materials through his Ph.D. research and continued it as a post doctoral scholar at the University of Pittsburgh and National Aeronautics and Space Administration (NASA). At the University of Pittsburgh, Bob was a National Institute of Health (NIH) fellow in the crystallography laboratory. Bob began teaching at the New York State College of Ceramics at Alfred University in 1970, and rose through the academic ranks to Professor of Ceramic Science in 1982, and became Professor Emeritus in 1996. He chaired the Material Science and Engineering Department at Ohio State from 1996 through 2002. Bob became co-chair of the School of Materials Science and Engineering at Georgia Tech in 2002. He enjoyed extended leaves to be a visiting scientist at Lawrence Livermore Laboratory (1977), National Bureau of Standards (1980, 1981), Sandia National Laboratory (1987), Siemens Central Research Laboratories Munich (1983, 1991), and the Université de Rennes (1995). During this time, he met and collaborated with many international scientists and fellow ICDD members who would also become lifelong friends.

He was the author of two textbooks, edited nine technical books, and contributed chapters to nine books and encyclopedias. He held eight patents, and published over 265 papers on materials and materials characterization which have been cited by other authors more than 2000 times. Bob
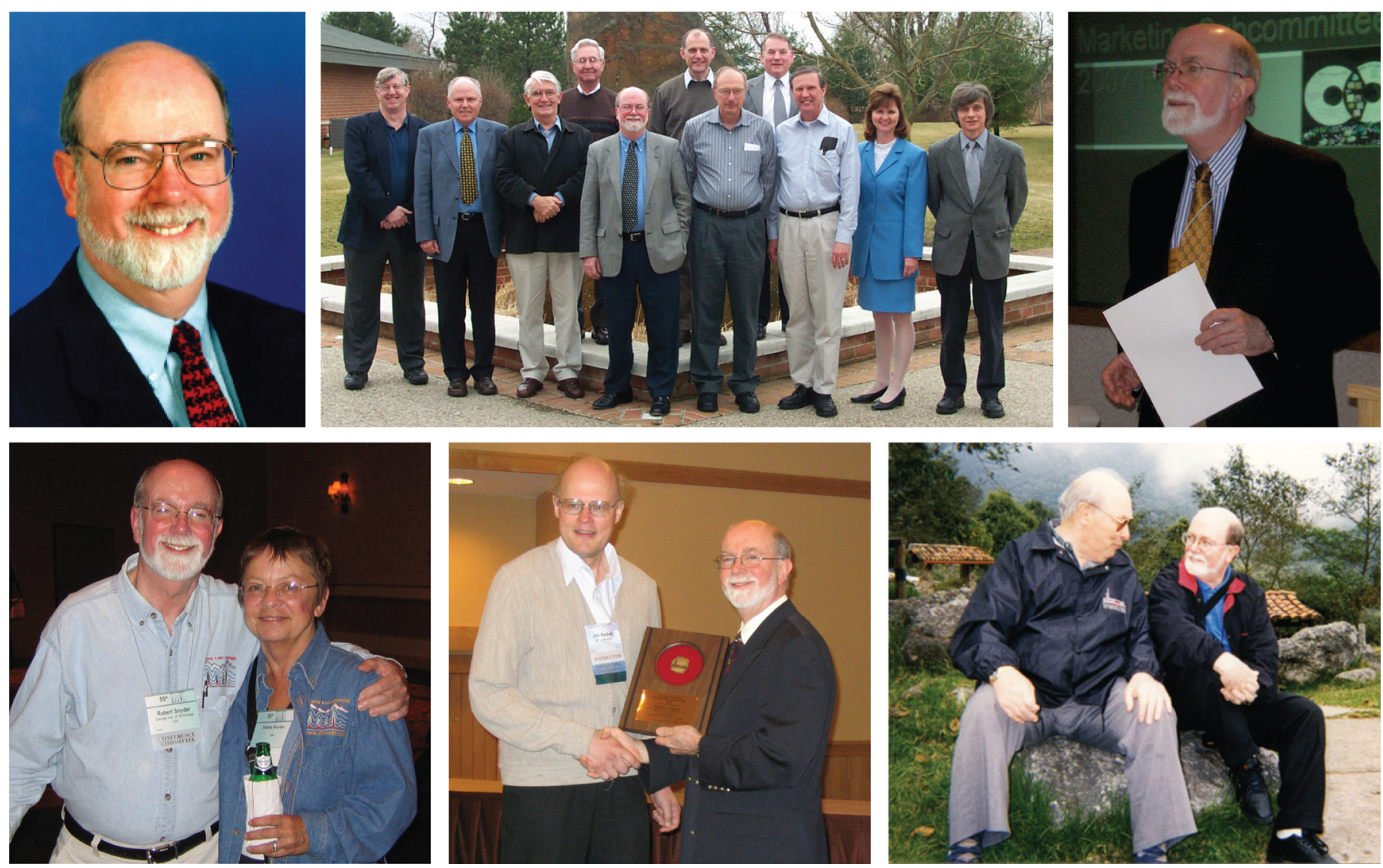

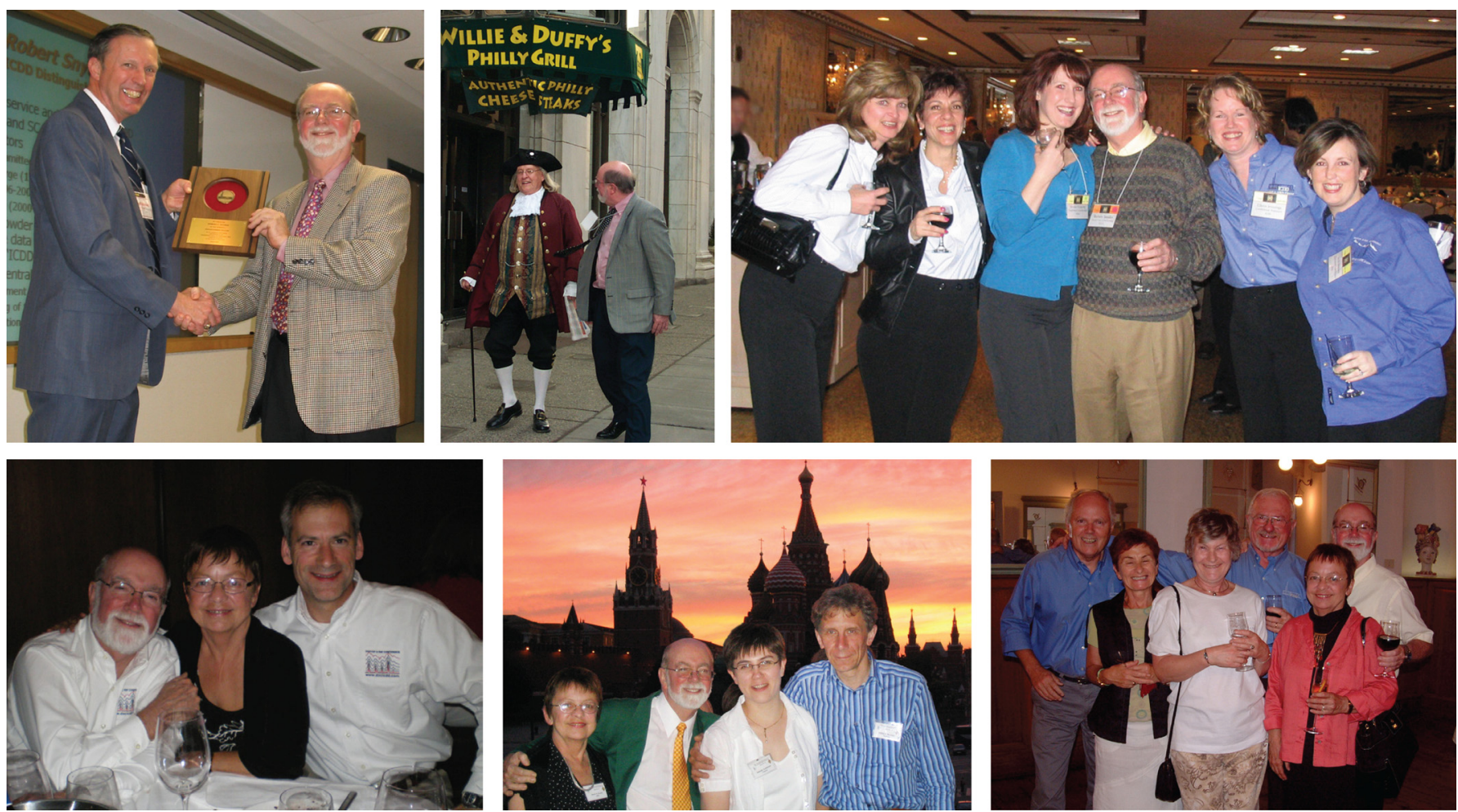

presented over 1000 talks around the world with over 40 plenary and keynote lectures. His fundamental textbook "Introduction to X-ray Powder Diffractometry," that Bob wrote with his close friend Ron Jenkins, has been used and distributed to hundreds of students attending ICDD workshops and clinics for over 15 years.

Bob always had a passion for all types of X-ray analysis as applied to solid state materials. He was Chairman of the Board of the ICDD from 1996 to 2000, as well as a board member in consecutive terms from 1986 to 2004. He served as the Chair of the Marketing Committee since 2005. As board member and chairman, Bob promoted alliances with other database organizations that directly led to the dramatic growth of the Powder Diffraction File over the last 15 years.

During his lifetime, Bob was also a champion for developing software and automated analysis programs for powder diffraction. He served as a member of the Denver X-ray Conference Organizing Committee and was the current chairman of that group. For many years, he served as an editor for the proceedings of the conference, Advances in
X-ray Analysis. He was a Principal Editor for the journal Materials Research and the Journal of the American Ceramic Society. Bob chaired the High Resolution Neutron Powder Diffraction research team at Brookhaven National Laboratory and was on the executive committee of beamlines X3 and X7 at the Argonne National Synchrotron Light Source. He was chair of the founding committee for the International Society of X-ray Analysis. He also chaired numerous committees of the American Crystallographic Association and was a member of the International Union of Crystallography Commission on Powder Diffraction. He was also a founder for the US-Japan Workshop series on Superconductivity from 1989 to 1997.

For his numerous contributions, Bob has received several awards which include:

- Distinguished Fellow, International Centre for Diffraction Data, 2005

- Hanawalt Award, International Centre for Diffraction Data, 2004 TMS Leadership Award, 2002
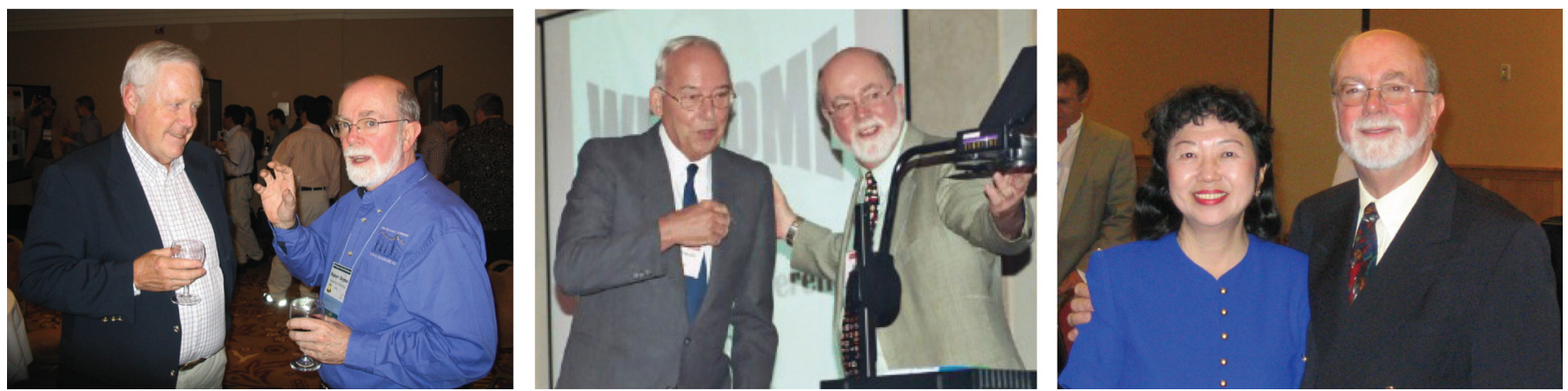
- Fellow, American Society of Metals, 1999

- American Ceramic Society Outstanding Educator, 1999

- Fellow, American Ceramic Society, 1993

- Chancellors Award for excellence in teaching, Alfred University, 1980

During his career, Bob formed many lasting relationships with members of the international community. Through his passion and friendship, he impacted the field as an innovator, teacher, administrator, and mentor. ICDD will be collecting remembrances (i.e., photos and stories) of Bob's life to present to his family. If you would like to contribute, please contact us at shertz@icdd.com.

Sincerely, Tim Fawcett ICDD Executive Director 